\title{
A New Approach to Teach Mechanics of Material Through Touching Experience
}

\author{
Yao George C. ${ }^{1}$, Kuo Keng-Chang ${ }^{2}$, Hsueh Cheng-Luen ${ }^{3}$, Tang Yao ${ }^{4}$ \\ ${ }^{1}$ Department of Architecture, National Cheng Kung University, Tainan, Taiwan \\ ${ }^{2}$ Department of Construction Engineering, National Kaohsiung First University of Science and Technology, Kaohsiung, Taiwan \\ ${ }^{3}$ Department of Architecture, National Cheng Kung University, Tainan, Taiwan \\ ${ }^{4}$ Institute of Education, National Cheng Kung University, Tainan, Taiwan
}

\section{Email address:}

gcyao@mail.ncku.edu.tw (Yao George C.), kkuo@nkfust.edu.tw (Kuo Keng-Chang), clhsueh@mail.ncku.edu.tw (Hsueh Cheng-Luen), alextang@mail.ncku.edu.tw (Tang Yao)

${ }^{*}$ Corresponding author

\section{To cite this article:}

Yao George C., Kuo Keng-Chang, Hsueh Cheng-Luen, Tang Yao. A New Approach to Teach Mechanics of Material Through Touching Experience. American Journal of Civil Engineering. Vol. 4, No. 4, 2016, pp. 143-148. doi: 10.11648/j.ajce.20160404.13

Received: April 8, 2016; Accepted: May 19, 2016; Published: June 2, 2016

\begin{abstract}
Recent advancement in building structural analysis by computer has changed the structural analysis work in the building professional. Nowadays, professionals can read output from the computers and will need a good structural concept to judge the validity of the analysis and to verify the calculated result. This change of structural analysis work sequence prompted us to reconsider the pedagogy in the Strength of Material class taught in the Architecture schools at the university level. This paper presents a new pedagogy in teaching Strength of Material class in the Department of Architecture at National Cheng Kung University in Taiwan. This new pedagogy is experiment-oriented in teaching different units of the Strength of Material in contrast to the math-oriented approach popularly used in most of the Engineering schools. New experiments emphasize on visually observable mechanical behavior so that students can visually inspect the deformation of members when subjected to different types of loadings. Three modules, they are lecture, experiment, and public presentation, are designed into the weekly class to enhance learning efficiency.
\end{abstract}

Keywords: Experiment-Oriented, Structural Concept, Mechanics of Materials, Architecture

\section{Introduction}

The exterior form and structure of a building act like the two sides of a coin. In designing innovative spaces, the structure serves both as a pivotal agent of imagination and ingredient for the creation of beauty [1]. As famously stated by an esteemed Japanese structural engineer Tsuboi Yoshikatsu [2] "The beauty of architecture comes hand in hand with a rational structural system." For this reason, imparting an understanding of structural concepts has been an integral part of the architectural curriculum at universities worldwide.

The planning of teaching material for structural courses at architectural schools in Taiwan has always proven a challenge. Instructors of structural courses often struggle to design appropriate course content for mechanics that can familiarize students with structural concepts. Conventionally, structural courses have been delivered as class presentations. For each topic, the instructor applies mathematical models to work out the forces and deformation or the relationship between stresses and strain, from which equations are derived to calculate structural reactions such as deformation or cross-sectional strengths. This approach is pedagogically ideal for rigorous and comprehensive knowledge systems. The drawback is its unilateral nature makes it hard to engage students, while the lack of stimulus is also not conducive to drawing their attention.

There are other reasons the conventional approach for teaching structural mechanics at engineering schools is at odds with the current educational environment at Taiwanese 
architectural schools:

1) A heavily loaded design curriculum occupies most of students' energy, leaving them little room to study engineering courses and therefore limiting the depth of the content that can reasonably be taught in structural courses.

2) Structural courses at conventional engineering schools often use mathematical models to explain mechanical behavior, so students with an insufficient foundation in mathematics have a hard time using commonly available textbooks.

3) There is a gap between the structural competency required by students in architectural design and the equations they learn at structural mechanics courses during their junior years, therefore diminishing their interest in studying structural courses.

In an era where computer-aided structural analysis is readily used throughout all stages of design [3], we find the mathematically equations mentioned above practically irrelevant in real-life structural calculations for designers, because all the computing can be accomplished by software. What design practitioners need, given all the computed data from structural analysis, is a strong understanding of structural concepts to determine the rationality of the results and verify the basic assumptions of the model.

As such, the latest pedagogical philosophy in structural engineering is to equip students with sufficient structural concepts, rather than teaching them how to derive equations. [4] The same idea can be applied to structural courses in architectural education. Recently, different approaches are developed for this goal in different architectural school based on the needs of their students. [5] This study turns away from the teaching model that builds structural concepts through equation-driven teaching and substantial experience in structural calculations. Instead, we apply the idea of "seeing and touching structural concepts", proposed by University of Manchester professor Bell [6], in developing a series of visually accessible syllabuses for teaching structural models. Rather than learning structural concepts through conventional mathematical tools, students shape their understanding by engaging in visible structural maneuvers complemented by in-class explanations of real-life examples in applying equations. This pedagogy utilizes a sensory approach, i.e. vision, to intrigue students and develop their competence. A similar approach has been adopted in structural courses at some civil engineering faculties [7], demonstrating its growing acceptance at various faculties in universities.

\section{Syllabus}

The compulsory structural mechanics courses in the four-year architecture program at National Cheng Kung University (NCKU) are as follows: structural behavior (Year 1 Term 2), strength of materials (Year 2 Term 1), structures (Year 2 Term 2), structural systems (Year 3 Term 1), reinforced concrete and steel Design (Year 3 Term 2). Strength of materials appears to present the most challenge to students of all the courses. This course introduces the deformation of members and relationships between internal stresses and strains when external forces are applied.

Because the content is critical for familiarizing students with concepts in structural mechanics, we developed a new approach to teach this class by the theory introduced above. This study initially targets a few key units in strength of materials to design a set of simple and interesting experiments that students can operate on their own (Table 1). They can then familiarize themselves with the relationship between forces and deformation by actually seeing the deformation. Since the deformation is visible to the eye, students take away a strong mental impression. Then, examples in engineering applications of the equations involved in the chapters are discussed in class with the help of textbooks, captivating students with practical applications. Finally, students are asked to analyze and review the experiment data in order to reinforce their understanding $[8,9]$.

Table 1. Lab units in the new strength of materials class.

\begin{tabular}{|c|c|c|c|}
\hline Unit & Topic & Unit & Topic \\
\hline 1 & $\begin{array}{l}\text { Internal forces, external } \\
\text { forces and stresses }\end{array}$ & 8 & Horizontal shear stresses \\
\hline 2 & Modulus of elasticity E & 9 & Bending moment experiment \\
\hline 3 & Shear and shear strain & 10 & $\begin{array}{l}\text { Cantilever beam: span and } \\
\text { deflection at the center }\end{array}$ \\
\hline 4 & Creep & 11 & $\begin{array}{l}\text { Deflection of different } \\
\text { connections }\end{array}$ \\
\hline 5 & Plane stresses & 12 & Buckling \\
\hline 6 & $\begin{array}{l}\text { Torsional stiffness and } \\
\text { cross-sectional shapes }\end{array}$ & 13 & $\begin{array}{l}\text { BRB (Buckling Restrained } \\
\text { Brace) }\end{array}$ \\
\hline 7 & $\begin{array}{l}\text { Torsional failure } \\
\text { characteristics }\end{array}$ & 14 & $\begin{array}{l}\text { LTB (Lateral Torsional } \\
\text { Buckling) }\end{array}$ \\
\hline
\end{tabular}

The study materials comprise three modules as detailed below:

1) Lecture: The contents of the lectures are taught by the instructor. Focus is placed on the engineering application of equations already derived in conventional mechanics, such as external forces and deformation. Take creep for example: real-life engineering failures caused by excessive creep in chemical anchors and the serious resulting damage are used to supplement explanations on the common characteristics of creep. (Fig. 1)

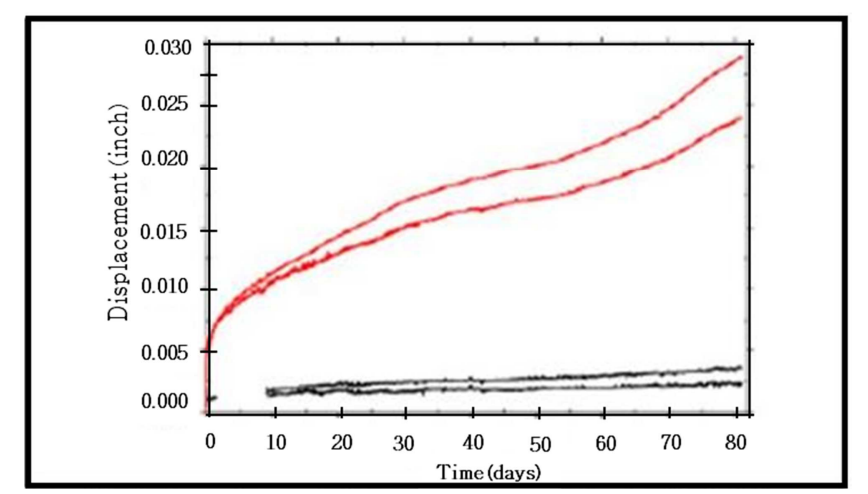

(a) Creep in different adhesives 


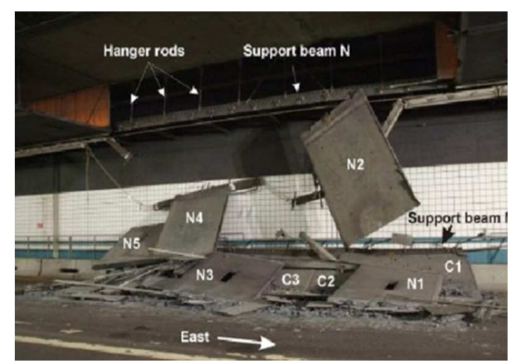

(b) Damage to hanger due to adhesive failure

Figure 1. Engineering failure caused by creep in adhesives.

2) Laboratory: In the lab module, the teaching assistant leads students in conducting experiments, with a focus on deformation that is visible or can be photographed with a camera or measured with simple equipment. The teaching assistant must design the experiment according to the objective of the unit and select appropriate materials in order to demonstrate the characteristics covered in the unit. Take for example an experiment on buckling: we have designed an experiment using a plastic ruler and an electronic scale, where students can read the load values causing the buckling as they apply pressure to the top of the ruler (Fig. 2). An intermediate support is then added to stimulate higher-mode buckling, allowing students to actually measure and see the higher load values required in the second-mode buckling [10].

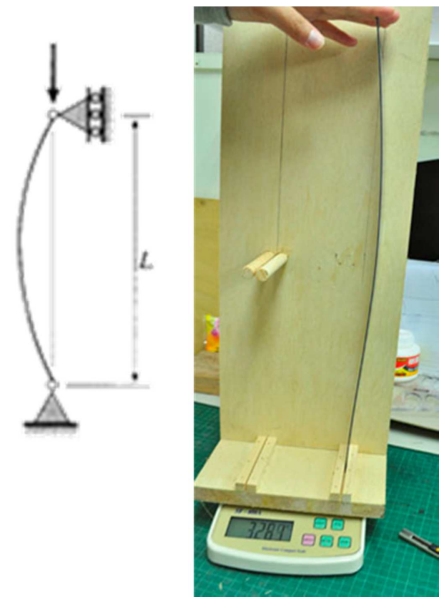

(a) Basic buckling

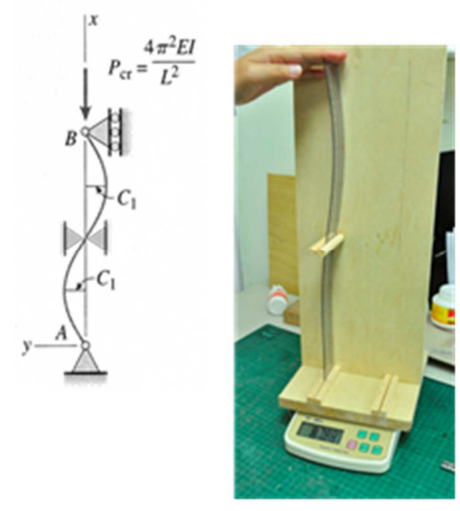

(b) Second mode buckling

Figure 2. Experiment on buckling load.
3) Public Presentation: Students conduct their own experiments, record data, analyze and compile reports in this module. Focus is placed on the processing of experiment data, discussing equations covered in the textbooks and the accuracy of the experiments, and examining possible causes of errors. Aside from submitting weekly reports, two teams of students must make an oral presentation followed by the instructor's comments and questions from their peers.

Hence, the course seeks to familiarize students with structural concepts by combining theoretical understanding and experiential learning. The textbooks and lab component for two units will be illustrated in the following chapter.

\section{Examples and Analysis}

1) Bending moments and deflection in beams

Since the relationship between bending moments and stress are is very important, key equations such as those for bending moments (Fig. 3a) and common deformation equation (Fig. 3b) will be explained to students first. As the main objective is to help them understand the close relationship between area moment of inertia and bending moment, it may be further explained in the follow-up examples that a deeper section should be used where the structure carries greater bending moment. This ensures efficient use of the section and reduced deformation (Fig. 4). [11]

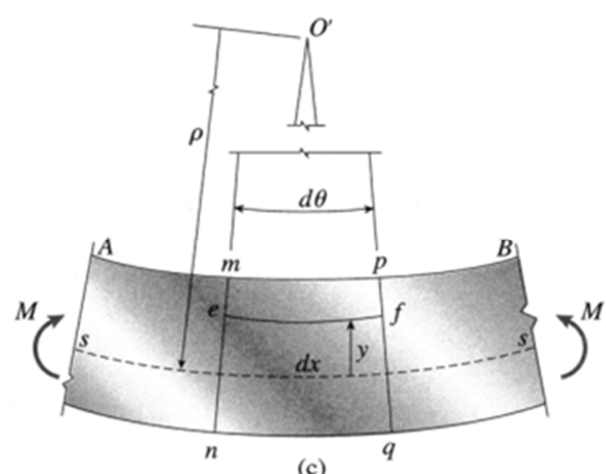

(c)

$$
\begin{gathered}
\sigma_{\mathrm{x}}=\frac{\mathrm{M}_{\mathrm{z}} \cdot \mathrm{y}}{\mathrm{I}_{\mathrm{z}}} \\
\sigma_{\mathrm{x}}=\mathrm{E} \cdot \varepsilon_{\mathrm{X}}=(-1) \cdot \mathrm{E} \cdot \mathrm{k} \cdot \mathrm{y}
\end{gathered}
$$

(a) Relationship between stress and external forces

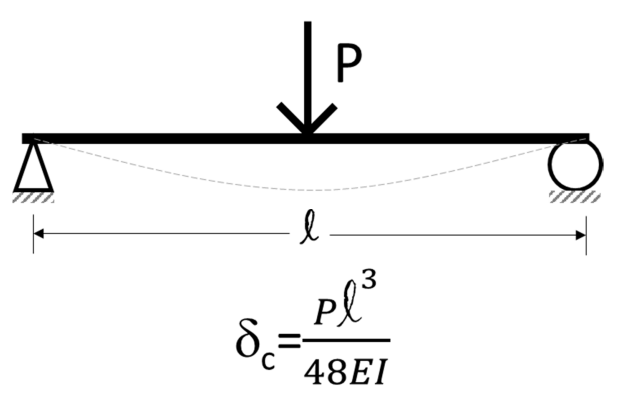

(b) Equation for simple beam deformation

Figure 3. Examples of equations and relationships for bending moment. 


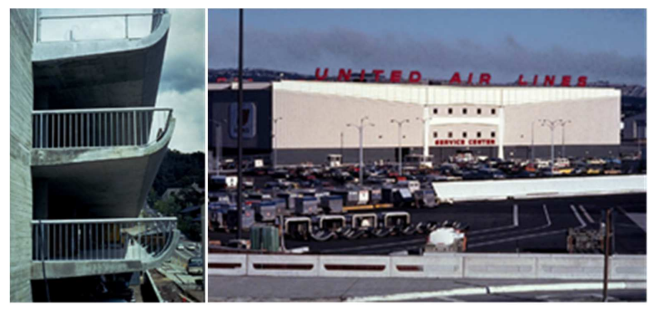

Figure 4. Examples of designing for bending moment --a deeper cross section is used on the cantilevered structure where the bending moment is greater.

The lab component for this unit is divided into two parts. Part 1 compares the I values and deflections at center for different cross sections of beams and then compare them with theoretical stress values. Part 2 calculates the radius of curvature for bending deformation. The experiment in Part 1 compares two members with different cross sections (Fig. 5a). By actually measuring the deformation of simply supported members built of balsa wood and under loading (Fig. 5b), students gain an insight into the close relationship between members with different moments of inertia and their deformation. To facilitate measurement, we used a non-contact laser displacement meter to achieve higher resolution.
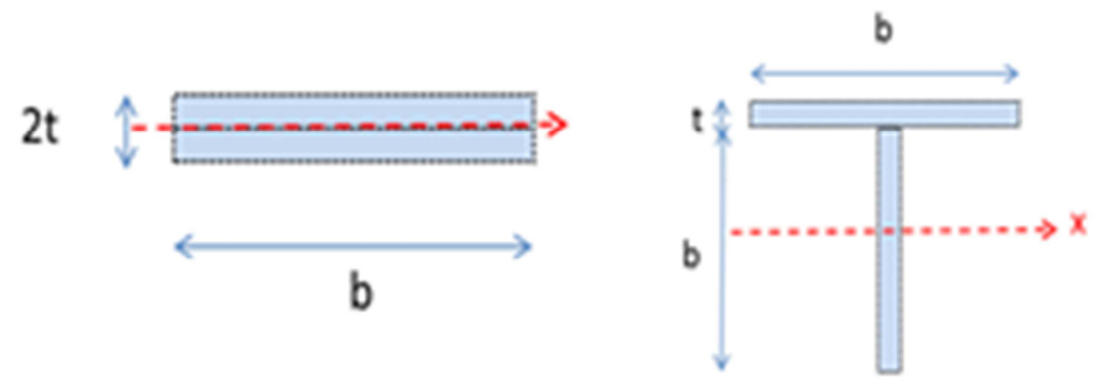

(a) Members with different cross sections
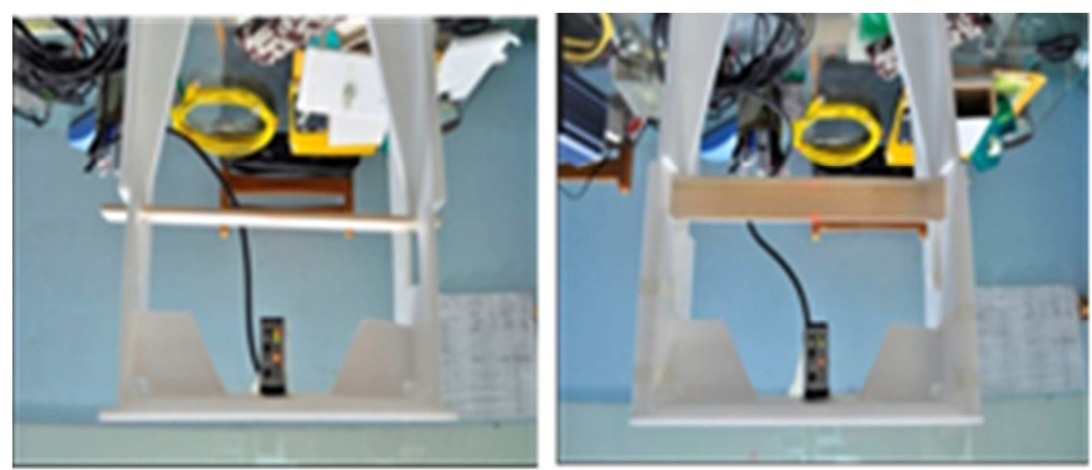

(b) Measuring deformation under equal loads

Figure 5. Relationship between the moment of inertia and deformation of members.

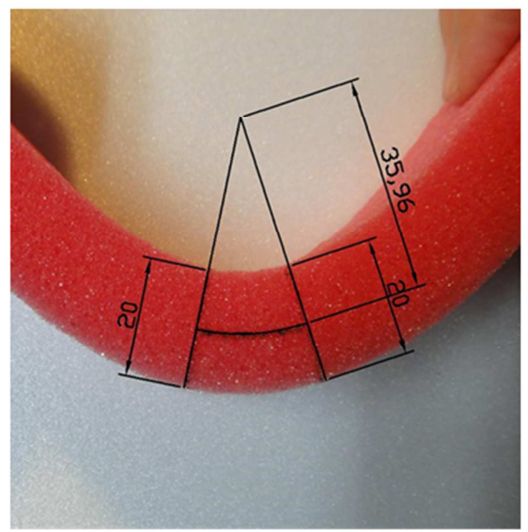

$$
\varepsilon_{\mathrm{X}}=\frac{y}{\rho}=\frac{-(20 \div 2)}{35.96}=-0.2781
$$

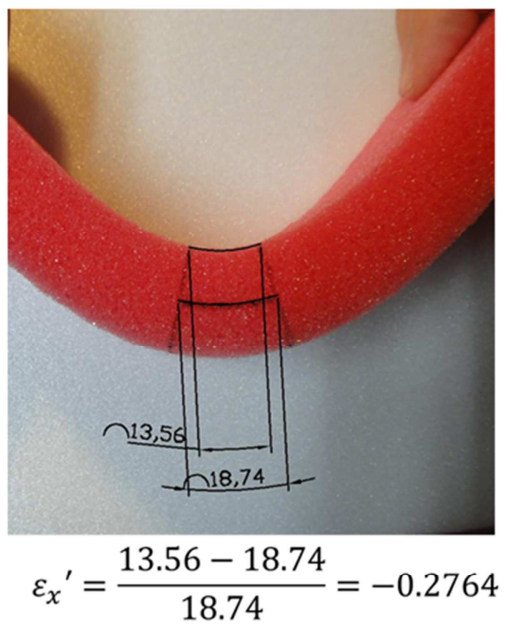

(a) Calculating strain by measuring the deformation (curve radius)

(b) Measuring the strain directly

Figure 6. Experiment on the bending deformation of a sample sponge. 
In the experiment in Part 2, the central axis is drawn on a piece of bendable sponge; the test sample is bent with hands, and the photographs are imported into AutoCAD for processing and analysis. Students find the radius of curvature, $\rho$, and then calculate the strain at the top surface of the member after compression, using the equation (Fig. 6a). They then sketch the curve of the top surface, measure its actual length and then find the strain. Finally, they calculate the error between the number they get from the equation and actual measurement. (Fig. 6b)

2) Horizontal shear in beams

Shear acting on a beam includes vertical and horizontal shear stresses. The main objective of this unit is to help students understand the relationship between these two types of shear stresses. Therefore, the cause of horizontal shear stresses will be explained first (Fig. 7) and the distribution of shear stresses on a rectangular beam and the corresponding equation will be detailed.
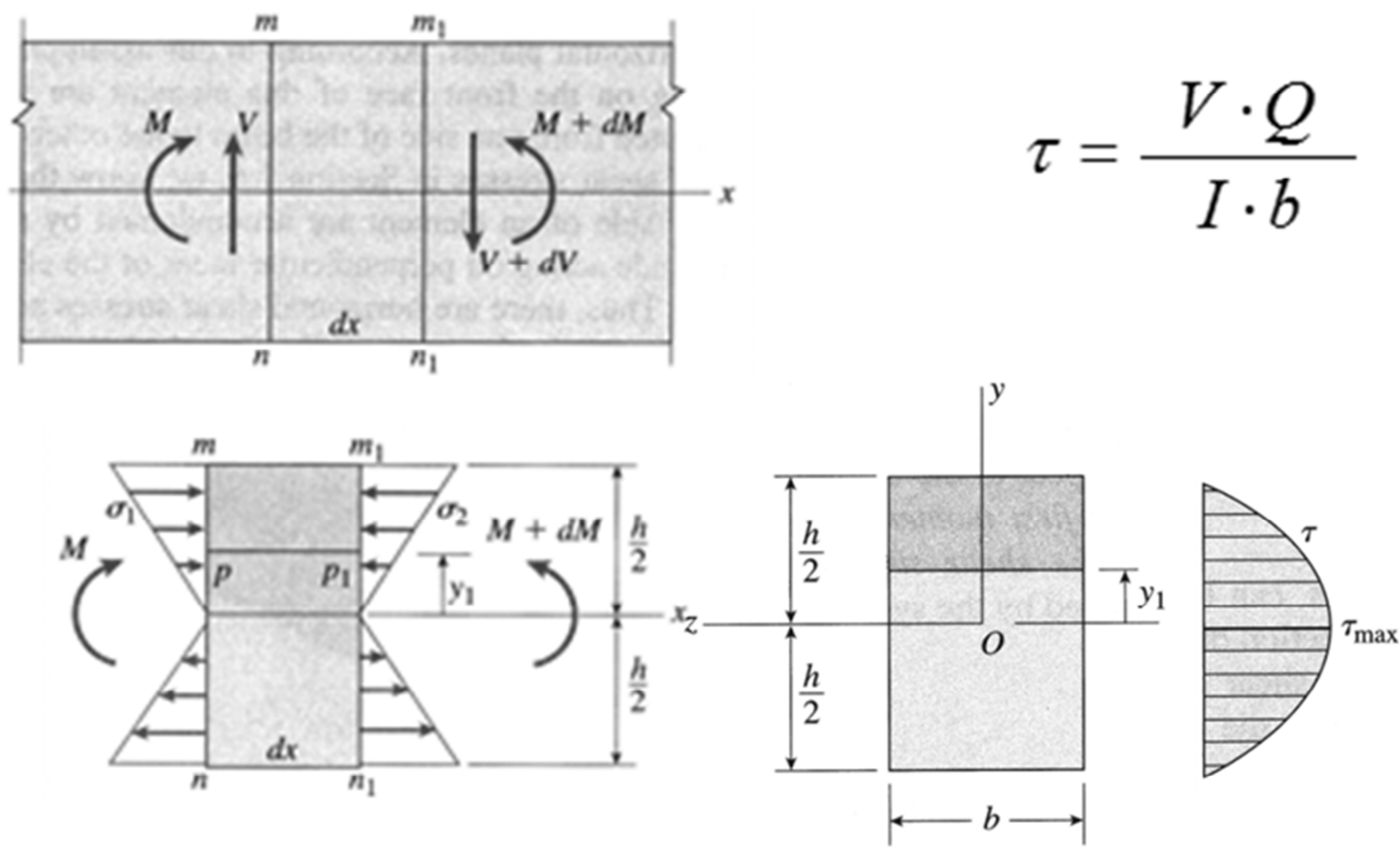

Figure 7. Introduction of the theory on horizontal shear stresses.

The engineering example used in this unit is shear design for steel I-beams. The reason why the web area of the cross section is used in the design of most steel beams (Fig. 8a) and the role played by shear stud is explained (Fig. 8b)

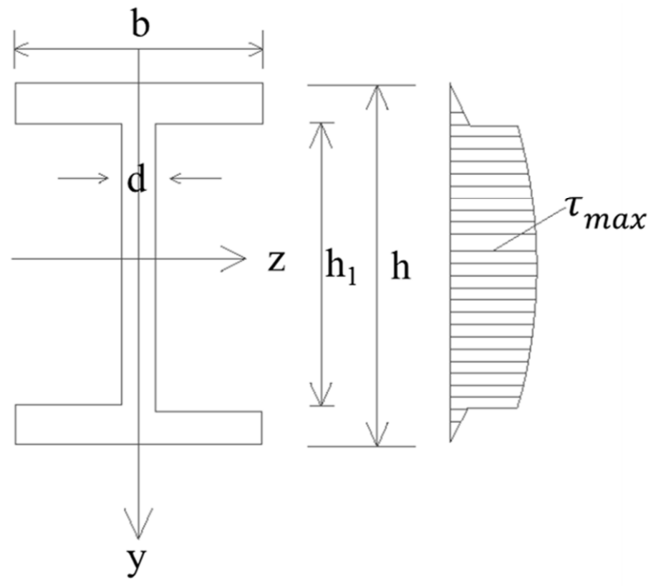

(a) Distribution of horizontal and vertical shear stresses
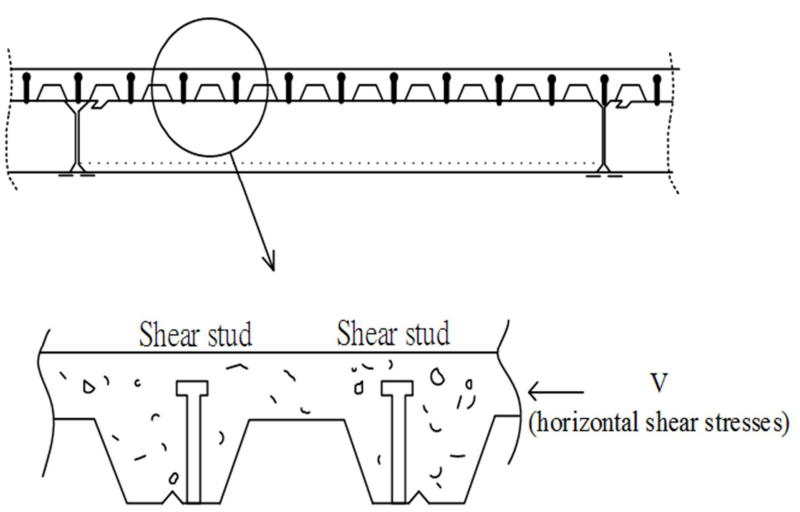

(b) Shear studs resist horizontal shear stresses

Figure 8. Engineering example of horizontal shear stresses.

This unit includes two experiments. The first aims to help students realize horizontal shear stresses cause relative movement and result in relative deformation if there is not a sufficient resisting mechanism. A simple beam structure 
made from two erasers is loaded at center to generate deformation. Erasers are used because their low stiffness results in visible deformation. (Fig. 9)

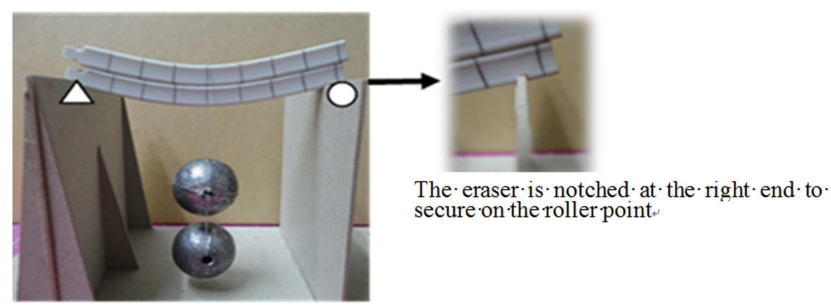

Figure 9. Horizontal shear causing deformation.

In the second experiment, foam board is used to make two sets of double-layered beams. One set is fastened with screws that act as shear studs, and the other set has no screws (Fig. 10). Equal loads are applied to the center of both sets, students observe the deflection of the center points of both beams, and deformation on both types of beams is explained.
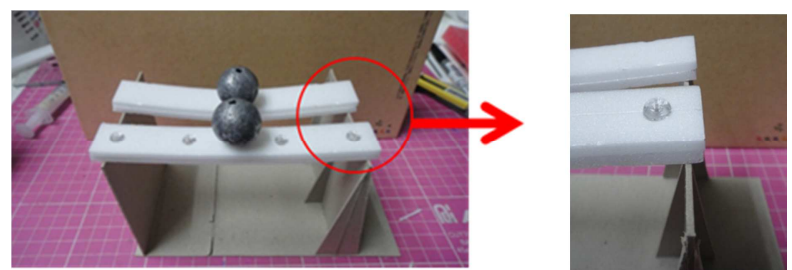

Figure 10. Comparing deformation between plates with and without connections.

\section{Conclusions}

Strength of materials is a very important structural course in the architectural curriculum. It is critical in familiarizing students with structural concepts because different types of external forces (e.g. axial force, bending moment and torque), member deformation and the relationships between internal forces are introduced. However, the traditional pedagogy of explaining mechanical behavior using mathematics often impedes architectural students' understanding of the underlying concepts in mechanics. Thus, this study proposes using experiments with visible models to help achieve this goal.

The lab content for 14 units in strength of materials is proposed herein. It has been tested over two years and the design for Year-3 courses is now underway. The students are first engaged in class through introduction to equations and relevant examples on the textbooks. Then, the lab component with visible features enables them to examine the applicability of the equations and secure a strong impression.
Finally, students conduct oral presentations and peer discussions, gaining full insight into strength of materials.

We intend to share the lecture notes for this course online, with the hope that teaching professionals interested in developing this curriculum will collaborate and promote this new pedagogy. Beginning in 2016, we plan to compile new textbooks for various structural courses, and we cordially invite your contribution in this endeavor.

\section{Acknowledgements}

Special thanks for generous support from National Science Council's Research Program No. MOST 103-2511-S-006-009.

\section{References}

[1] Charleson, A. W. (2005), Structure As Architecture: A Source Book For Architects And Structural Engineers. Architectural Press, Oxford.

[2] Architectural Institute of Japan (2001), Spatial Structures Seismic Design and Realization in Japan, Maruzen Publishing.

[3] Computers \& Structures, Inc. (2015), CSI Analysis Reference Manual, Computers \& Structures, Inc.

[4] An Innovative Tool for Teaching Structural Analysis and Design, IBK, vdf Hochschulverlag AG, Swissland.

[5] Dytoc, Bronne, Graphic Learning Strategies to Motivate Structures Education in Architecture, 5th Annual International Conference on Architecture, 6-9 July 2015, Athens, Greece.

[6] Ji, T. and Bell, A. (2008), Seeing and Touching Structural Concepts, Higher Education Press, Beijing.

[7] Tao, Y., Liu, Z., Chen, J., Li, G. and Wang, Q. (2012), Teaching Concrete Structural Design Theories by Visualizing and Feeling of Structural Concepts, Journal of Southeast University (Philosophy and Social Science), 14 (S2), 191-194.

[8] Ján Ilkovi. (2014), To think in architecture, to feel in structure: Teaching Structural Design in the Faculty of Architecture. Global Journal of Engineering Education. 16: 59-65.

[9] Kolb, D. A. (1984), Experiential learning: Experience as the source of learning and development, Englewood Gliff, NJ.

[10] Hibbeler, R. C. (2011), Mechanics of Materials, Prentice Hall.

[11] Gere, J. M. and Goodno B. J. (2013), Mechanics of Materials, Cengage Learning. 